\title{
Original article (short paper) \\ Effect of a rehabilitation program using virtual reality for balance and functionality of chronic stroke patients
}

\author{
Wagner Henrique Souza Silva \\ Gleyson Luiz Bezerra Lopes \\ Kim Mansur Yano \\ Nathália Stephany Araújo Tavares \\ Isabelle Ananda Oliveira Rego \\ Fabrícia Azevedo da Costa Cavalcanti \\ Universidade Federal do Rio Grande do Norte, Natal, RN, Brazil
}

\begin{abstract}
This study aimed to investigate the effect of a rehabilitation program using virtual reality (VR) in addition to conventional therapy for improvement of balance (BERG scale) and functional independence (FIM scale) in chronic stroke patients. Ten individuals, mean age of 51.4 ( \pm 6.7 years), participated of eight 60 -minute sessions comprising kinesiotherapy (15min), Nintendo Wii (30min) and Learning transfer (15min) exercises. After training, nonparametric statistical analysis showed significant improvement in total FIM $(p=.01)$ and BERG scores $(p=.00)$, and in some of their subitems: FIM - dressing lower body $(p=.01)$, transfer to bathtub/shower $(p=.02)$ and locomotion: stairs $(p=.03)$; BERG - reaching forward with outstretched arm $(p=.01)$, retrieving object from the floor $(p=.04)$, turning $360^{\circ}(p=.01)$, placing alternate foot on step $(p \leq .01)$, standing with one foot in front $(p=.01)$, and one leg stand $(p=.03)$. These findings suggest a positive influence of virtual reality exercises adjunct to conventional therapy on rehabilitation of balance and functionality post stroke, and indicate the feasibility of the proposed VR-based rehabilitation program.
\end{abstract}

Keywords: rehabilitation, virtual reality, daily living activities, postural balance

Resumo - "Efeito de um programa de reabilitação utilizando realidade virtual para o equilíbrio e funcionalidade de pacientes com AVC crônico." Este estudo objetivou investigar o efeito de um programa de reabilitação utilizando adição de Realidade Virtual (RV) à terapia convencional para melhora do equilíbrio (Escala de BERG) e independência funcional (escala MIF) de pacientes com AVC crônico. Dez indivíduos, idade média de 51,4 ( \pm 6,7 anos), participaram de oito sessões de 60 minutos incluindo exercícios de cinesioterapia (15min), Nintendo Wii (30min) e transferência de aprendizagem (15min). Após o treinamento, análise estatística não paramétrica mostrou evolução significativa nos scores totais das escalas MIF $(p=0,01)$ e BERG $(p=0,00)$, e em alguns de seus subitens: MIF - vestir membros inferiores $(p=0,01)$, transferência para o chuveiro $(p=0,02)$ e locomoção: escadas $(p=0,03)$; BERG - alcance de braço $(p=0,01)$, coletar objeto no chão $(p=0,04)$, girar $360^{\circ}(p=0,01)$, pé degrau alternado $(p \leq 0,01)$, pé à frente $(p=0,01)$, e apoio unipodal $(p=0,03)$. Estes achados sugerem uma influência positiva de exercícios com realidade virtual adjuntos à terapia convencional na reabilitação do equilíbrio e funcionalidade pós AVC, e indicam a viabilidade do programa de reabilitação baseado em RV conforme proposto.

Palavras-chave: reabilitação, realidade virtual, atividades cotidianas, equilíbrio postural

Resumen - "Efecto de un programa de rehabilitación utilizando la realidad virtual para el equilibrio y la funcionalidad de los pacientes con accidente cerebrovascular crónico." El objetivo de este estudio fue investigar el efecto de un programa de rehabilitación combinado de Realidad Virtual (RV) con terapia convencional en pacientes con accidente cerebrovascular crónico para la mejora del equilibrio (escala de BERG) y la independencia funcional (escala MIF). 10 sujetos, con una edad media de 51,4 ( \pm 6,7 años), participaron en ocho sesiones rehabilitación de 60 minutos. Las sesiones incluyeron ejercicios de kinesioterapia (15min), Nintendo Wii (30min) y transferencia del aprendizaje (15min). Tras el entrenamiento, el análisis estadístico con test no paramétricos confirma una evolución significativa en las puntuaciones totales en las escalas MIF $(p=0,01)$ y BERG $(p=0,00)$ y en alguno apartados de las escalas: MIF - vestido de los miembros inferiores $(p=0,01)$, uso de la ducha $(p=0,02)$ y locomoción: escaleras $(p=0,03)$; BERG - alcance del brazo $(p=0,01)$, recuperar un objeto del suelo $(p=0,04)$, girar $360^{\circ}(p=0,01)$, pies en escalones alternos $(p \leq 0,01)$, pie al frente $(p=0,01)$ y apoyo unipodal $(p=0,03)$. Estos resultados sugieren una influencia positiva de la VR como complemento a la terapia convencional en la rehabilitación del equilibrio y capacidad funcional tras un accidente cerebrovascular y confirman la viabilidad del programa combinado de rehabilitación propuesto.

Palabras claves: rehabilitación, realidad virtual, actividades cotidianas, equilibrio postural 


\section{Introduction}

Stroke is one of the primary causes of death and functional disability in the world (Lavados et al., 2007). It leads to many sequelae affect balance control and suitable performance of activities of daily living (Nichols-Larsen, Clark, Zeringue, Greenspan, \& Blanton, 2005), thereby weakening independence and health related quality of life (Belgen, Beninato, Sullian, \& Narielwalla, 2006; Bonan et al., 2004). Different types of interventions have been developed with the purpose of improving rehabilitation post stroke (Langhome, Coupar, \& Pollock, 2009). Most of these techniques, however, rely on consistent repetition of particular movements are frequently considered fatiguing, aimless and time demanding (Adamovich et al., 2002; Botelho \& Vaghetti, 2010). The application of virtual reality to promote motivation during therapy is increasing and studies have shown it to be successful. It has been related to higher levels of satisfaction and adherence to treatments (Newton \& Russel, 2008), whereas more evidence of its effectiveness as a therapeutic tool in rehabilitation is still warranted (Levac \& Galvin, 2013).

Virtual Reality (VR) stands out as a computerized experience that simulates real-life situations in artificial environments while comprising sensory, cognitive, psychological and motor components (Rizzo \& Schultheis, 2001; Schiavinato, Baldan, Melatto, \& Lima, 2010). It promotes exercises based on contextualized goals, supporting personal engagement during interactions in dynamic and meaningful settings. In this perspective, virtual-based rehabilitation seems to be favored by tasks performed under adaptable conditions (Fung, Lamontagne, Malouin, McFadyen, \& Richards, 2006) where the perception of artificial stimuli modulates real physiological responses and actions. Nevertheless, many studies in virtual reality to date are based upon costly equipment that demand complex operation and customized facilities. These characteristics compromise the translation of experimental protocols to wider practice and lead to debate about the feasibility of this type of therapy (Mouawad, Doust, Max, \& McNulty, 2011).

Recent research has indicated the effectiveness and feasibility of Nintendo Wii as an affordable alternative to more complex devices applied in virtual reality interventions (Bernal-Sahún et al., 2010; Gil-Gómez, Lloréns, Alcañiz, \& Colomer, 2011). However, despite the promising results, empirical evidence is still sparse and likely refers to the application of virtual reality alone or compared to individual methods (Laver, George, Thomas, Deutsch, \& Crotty, 2012). Only a few studies have addressed the inclusion of virtual reality as a component of rehabilitation programs. Furthermore, only a fraction of these reports concern to stroke populations for which such application remains overlooked, particularly in regards to balance recovery (Li, Han, Sheng, \& Ma, 2015).

This study aimed to investigate the extent to which a virtual reality (VR)-based rehabilitation program affects measures of balance (BERG scale) and functional independence (FIM scale) of chronic stroke patients submitted to eight 60-minute therapy sessions in four weeks. It hypothesizes that the addition of Nintendo Wii balance training to conventional kinesiotherapy and learning transfer exercises is not only feasible, but can also lead to significant improvements in the outcome measures. The present study extends evidence on the application of virtual reality to clinical practice and proposes an alternative therapeutic protocol for treating chronic stroke populations.

\section{Methods}

\section{Research design}

This study consisted of a case series including individuals diagnosed with unilateral stroke and was approved by the Human Research Ethics Board of Federal University of Rio Grande do Norte (UFRN), no 333/December 2010. Six men and four women, recruited at the physiotherapy department of UFRN, participated in this trial. All subjects gave written informed consent before being enrolled. Inclusion criteria were: single episode of unilateral stroke confirmed by MRI, stroke onset time greater than six months, levels one and two on the Ashworth Scale for the lower paretic limb and ability to walk on a flat surface independently, with or without an assistive device. Exclusion criteria were: the presence of associated pathologies that caused neurological or orthopedic disorders affecting balance, cognitive impairments that hindered autonomy during gameplay and history of visually induced seizures.

\section{Evaluation tools}

The functional independence measure (FIM) was applied to assess post-stroke functionality. Developed by the American Academy of Physical Medicine and Rehabilitation, this instrument has been validated for research in Brazil (Battistella et al. 2004). Containing 18 items, the FIM measures six different domains in two sections: cognitive and motor. The latter, used in the present study, is composed of 13 items: 1.Eating, 2.Grooming, 3.Bathing/showering, 4.Dressing upper body, 5.Dressing lower body, 6.Toileting, 7.Bladder management, 8.Bowel management, 9.Transfers: bed/chair/ wheelchair, 10.Transfers: toilet, 11.Transfers, bathtub/shower, 12.Locomotion: walking/wheelchair, 13.Locomotion: stairs. Each item is scored from 1 to 7 based on level of independence, where 1 represents total dependence and 7 indicates complete independence. The total score can range from 13(minimum) to 91 (maximum). The higher the score, the more functionally independent one is.

In addition to the FIM, the Berg Balance Scale (BBS) was applied to evaluate balance under static and dynamic conditions. Validated in Brazil (Berg, Lombardi, Miyamoto, Natour, \& Ramos, 2004), the Berg Scale contains 14 items related to the performance of movements and coordination of body parts in completing functional activities widely present in daily life: 1.Sitting to standing, 2.Standing unsupported, 3.Sitting unsupported, 4.Standing to sitting, 5.Transfers, 6.Standing with eyes closed, 7.Standing with feet together, 8.Reaching forward with outstretched arm, 9.Retrieving object from floor, 10.Turning to look behind, 11.Turning 
360 degrees, 12.Placing alternate foot on step, 13.Standing with one foot in front, 14.Standing on one leg. Each item is scored from 0 to 4 , based on the subject's independence. The total score can range from 0 to 56 , with lower scores indicating poorer functioning.

\section{Procedures}

Participants agreed to attend eleven appointments including: the experimental rehabilitation program (8), pre-andpost-program assessments (2) and introductory practice (1). The first meeting was set for the pre-program assessment and included data collection with application of clinical instruments. At the second meeting, subjects were introduced to the clinical setting by creating their personalized avatar and briefly practicing virtual exercises using a Wii Balance Board (WBB). Through appointments three to ten, here called therapy sessions, subjects were submitted to eight 60-minute sessions of an experimental VR-based rehabilitation program, held twice a week, for 4 weeks. Each therapy session comprised three phases (therapeutic approaches): kinesiotherapy, virtual reality and learning transfer exercises. At the eleventh appointment, clinical instruments were reapplied for post-program assessment. A single investigator performed all assessments.

\section{Therapy sessions}

The first phase of a therapy session involved classic kinesiotherapy for the upper limb during 15 minutes. It included stretching, free exercises, light resistance exercises and postural adjustments followed by joint mobility.

The second phase comprised virtual reality exercises for 30 minutes. The setting enclosed a Nintendo Wii console connected to a 29" television and a Wii Balance Board ${ }^{\circledR}(\mathrm{WBB})$, located directly on the floor at a distance of 240 centimeters from the television screen. For safety reasons, a chair and a walker were positioned behind and in front of the WBB, respectively. The WBB has been validated as a strength platform to assess balance in human research (Brault, Craig, Ferguson, \& Young, 2011). It works with the Wii Fit Plus ${ }^{\circledR}$ software, which holds five categories of exercises: strength, yoga, aerobics, balance and advanced training. Seven games (exercises) from the balance category were used in this study. All participants performed the same sequence of games: balance bubble; penguin slide; soccer heading; tightrope and table tilt, with six minutes of practice for each game.

The third phase comprised learning transfer activities (Benda, 2006; Kaefer, Chiviacowsky, Meira, \& Go Tani, 2014) for 15 minutes. At this point, participants were asked to perform real-world exercises that included movements based on those practiced while engaging in virtual reality tasks, such as: straight line walking (resembling Tightrope) and heading a ball thrown at them by the therapist in various directions (resembling Soccer heading).

\section{Adaptation of therapy sessions}

Beginning at the fifth therapy session, one out of two extra games (ski jump and ski slalom) were added to the sequence of virtual games. Simulators of snow sports, these exercises are more challenging and worked as a progression within the treatment. They were added alternatively so as to avoid consecutive inclusion in the remaining four sessions. With the addition of a sixth game, the time for each virtual exercise was reduced from six to five minutes, keeping total virtual exposure time in 30 minutes.

All exercises were accomplished without therapeutic or assistive devices. Safety resources were used during the entire intervention, conducted in a laboratory adapted for the study. During therapy sessions, heart rate variability was tracked using a Polar ${ }^{\circledR}$ chest belt HR monitor.

\section{Statistical analysis}

Statistical analysis was performed using the Statistical Package for the Social Sciences (SPSS) 20.0 program, at a 5\% significance level. The quantitative variables were described by means and standard deviations. Inferential statistics using Spearman's correlation determined the association between data measured by both the Berg and FIM scales. Finally, Wilcoxon test verified differences between dependent samples before and after the intervention in order to assess possible effects of motor training with VR and conventional therapy on balance and functionality in the group under study.

\section{Results}

Ten individuals, six men, mean age of 51.4 ( \pm 6.7 years), participated in this study with eight virtual reality-based therapy sessions over the course of four weeks. Before the intervention, the main complaints were insecurity/difficulty in walking or remaining standing independently, reported by all patients. In addition, other problems reported at the initial assessment were hemiparesis (80\%), postural patterns (40\%) and aphasia (10\%). Only $20 \%$ had previous experience with video games, either as entertainment or therapy.

Statistical analysis revealed a positive effect of the exercise program based on the final total scores obtained on both scales: FIM $(p=.01)$ and BERG $(p \leq .01)$. FIM outcomes, expressed in Table 1, show an increase in all the items. However, in addition to "total score," improvements were only significant in three specific tasks: "dressing lower body" ( $p=.01)$, "transfers: bathtub and shower" $(p=.02)$ and "locomotion: stairs" ( $p=.03)$.

With respect to balance, Table 2 shows a significant rise in "total score" as well as in six other items: "standing forward with outstretched arm" ( $p=.01)$, "retrieving object from the floor" $(p=.04)$, "turning 360 degrees" $(p=.01)$, "placing alternate foot on step" $(p=.01)$, "standing with one foot in front" $(p=.01)$ and "one leg stand" $(p=.03)$. 
Table 1. Motor FIM Scale - Mean values before and after intervention.

\begin{tabular}{|c|c|c|c|}
\hline Task & Mean (before) & Mean (after) & $p$ value \\
\hline Eating & $5.2 \pm 0.9$ & $5.4 \pm 0.8$ & .31 \\
\hline Grooming & $4.9 \pm 1.7$ & $5.1 \pm 1.7$ & .15 \\
\hline Bathing/showering & $5.7 \pm 1.3$ & $6.0 \pm 1.2$ & .08 \\
\hline Dressing upper body & $5.4 \pm 1.2$ & $5.9 \pm 1.1$ & .05 \\
\hline Dressing lower body & $5.6 \pm 1.1$ & $5.8 \pm 1.1$ & $.01 *$ \\
\hline Toileting & $7.0 \pm 0.0$ & $7.0 \pm 0.0$ & $>.05$ \\
\hline Bladder management & $6.8 \pm 0.4$ & $6.9 \pm 0.3$ & .31 \\
\hline Bowel management & $7.0 \pm 0.0$ & $7.0 \pm 0.0$ & $>.05$ \\
\hline Transfers: bed/chair/wheelchair & $5.9 \pm 0.3$ & $6.2 \pm 0.4$ & .08 \\
\hline Transfers: toilet & $6.5 \pm 0.5$ & $6.7 \pm 0.4$ & .31 \\
\hline Transfers: bathtub/shower & $5.7 \pm 1.0$ & $6.2 \pm 1.0$ & $.02 *$ \\
\hline Locomotion: walking/wheelchair & $6.0 \pm 0.0$ & $6.1 \pm 0.3$ & .31 \\
\hline Locomotion: stairs & $4.4 \pm 1.5$ & $5.2 \pm 1.3$ & $.03 *$ \\
\hline Motor FIM total & $76.1 \pm 5.3$ & $79.5 \pm 5.9$ & $.01 *$ \\
\hline
\end{tabular}

Comparative analysis between motor FIM scores before and after a Wii ${ }^{\circledR}$ virtual reality-based rehabilitation protocol $(n=10)$. *Significant difference $(p<.05)$.

Table 2. BERG Balance Scale - Mean values before and after intervention.

\begin{tabular}{lccc}
\hline Berg task & Mean (before) Average & Mean (after) & $p$ value \\
\hline 1.Sitting to standing & $3.9 \pm 0.3$ & $4.0 \pm 0.0$ & .31 \\
2.Standing unsupported & $3.9 \pm 0.3$ & $4.0 \pm 0.0$ & .31 \\
3.Sitting unsupported & $4.0 \pm 0.0$ & $4.0 \pm 0.0$ & $>.05$ \\
4.Standing to sitting & $3.8 \pm 0.4$ & $4.0 \pm 0.0$ & .15 \\
5.Transfers & $3.9 \pm 0.3$ & $4.0 \pm 0.0$ & .31 \\
6.Standing with eyes closed & $3.9 \pm 0.3$ & $4.0 \pm 0.0$ & .31 \\
7.Standing with feet together & $3.4 \pm 1.2$ & $4.0 \pm 0.0$ & .15 \\
8.Reaching forward with outstretched arm & $3.0 \pm 0.8$ & $3.8 \pm 0.4$ & $.01^{*}$ \\
9.Retrieving object from floor & $3.4 \pm 0.5$ & $3.8 \pm 0.4$ & $.04^{*}$ \\
10.Turning to look behind & $3.2 \pm 0.4$ & $3.5 \pm 0.5$ & .08 \\
11.Turning 360 degrees & $2.3 \pm 0.4$ & $3.4 \pm 0.8$ & $.01^{*}$ \\
12.Placing alternate foot on step & $2.0 \pm 1.3$ & $3.5 \pm 0.9$ & $.00^{*}$ \\
13.Standing with one foot in front & $1.5 \pm 1.4$ & $3.1 \pm 0.8$ & $.01^{*}$ \\
14.One leg stand & $2.3 \pm 1.4$ & $3.2 \pm 1.1$ & $.03^{*}$ \\
Berg total & $41.3 \pm 4,9$ & $48.3 \pm 3.5$ & $.00^{*}$ \\
\hline
\end{tabular}

Comparative analysis between BERG scores before and after a Wii ${ }^{\circledR}$ virtual reality-based rehabilitation protocol $(n=10)$. $*$ Significant difference $(p<.05)$.

\section{Discussion}

This study investigated the extent to which a rehabilitation program using additional virtual reality (VR) to kinesiotherapy and learning transfer exercises affected measures of balance (BERG scale) and functional independence (FIM scale) of chronic stroke patients.

One advantage of adding virtual reality to conventional practices is that it combines very important elements of rehabilitations, such as locomotion, repetition and feedback, which are difficult to stimulate concurrently in a single session of conventional therapy. The general response to the proposed program was very positive, with total adherence of participants. However, despite the favorable data, study limitations were the small sample size and the absence of a control group.

A number of the individuals under study exhibited insecurity or even fear while performing virtual exercises. Nevertheless, no interruption was required and determination was evident in several instances, demonstrating the desire to win the game and personal commitment to the therapeutic objective. Similar behavior was reported by Lewis (Lewis, McPherson, Rosie \& Woods, 2011), whose research analyzed patients' perspectives regarding the use of virtual devices in the therapeutic process, which was considered to be pleasant, motivating and challenging.

Early in 2010 Bayley (Bayley et al., 2010) conducted a randomized study with 20 individuals that determined the feasibility and adherence potential of a virtual rehabilitation process in the treatment of stroke sequelae. Their discussion proposed that an important factor for such outcome was the large number of repetitions of specific movements associated with continuous feedback, two important catalyzers of the motor learning process. Corroborating these findings, over the course of our protocol, balance was continuously stimulated by postural adjustments required in goal-directed actions, also influenced by different scenarios and contexts. 
In these settings, where individuals represented by their avatars had to adjust their centers of gravity, motor and cognitive skills were integrated in a multitask model. The prospect of a forceful and repetitive purpose-based motor task, modulated by constant visual information about the recently executed action, seems to have contributed to enhance motor performance and the high level of adherence recorded. This therapeutic paradigm also appears to enable contextualized self-modulated motor activities based on multiple cues, as described in earlier publications (Austin \& Sigurdsson, 2008). Simultaneously, the scoring system of the games, following a reward model, appears to have played an important role in adherence and the individual perspective of participants regarding their own motor condition, with a high score synonymous with treatment progress.

Our data corroborate the findings reported by Schiavinato (Schiavinato et al., 2010) in a case study involving a patient with cerebral palsy, which showed a significant improvement in balance after Virtual Reality training. The study suggested that postural adjustments in anteroposterior and lateral deviations to reposition the center of gravity as a response to disturbances observed in a virtual setting were potentially favorable to enhance balance control and acquisition of new limits of stability. This hypothesis is reinforced by our findings, with an increase in total Berg score at the end of the intervention, particularly gains in the most challenging items of the scale, for which previously mentioned adjustments were highly necessary. This indicates relevant improvement in the performance of static and dynamic balance following VR based exercise, as observed in a study with 12 subjects assessed by the Berg scale after Wii-Hab therapy (Araujo, Barcala, Colella, Oliveira, \& Salgado, 2011).

Although the mutual influence of Berg and FIM on their total scores was not observed, the results suggest that a number of the subitems may be effect-related, given the similarity between the motor demand and final gain observed in the "alternate step" and "one leg stand" items of the BERG scale and the significant improvement obtained in "locomotion: stairs", "dressing lower body" and transfer to bathtub/shower" items of FIM. These tasks, for which sequential weight shifts are required, rely on hip dissociation and efficient limb coordination. Such actions, later reinforced during transfer exercises, were constantly simulated in tightrope, penguin slide and soccer heading, besides favored by postural adjustments demanded in balance bubble and table tilt.

For functional locomotion, as proposed by Linder (Linder, Milidonis, Reinthal, \& Szirony, 2010), the continuous repetition promoted by therapy associated with virtual games favors motor relearning and its application in functional tasks of daily life, accelerating social reintegration and autonomy. This was expressed in the FIM scores, indicating that the proposed rehabilitation program is potentially effective on functional gain after stroke. This improvement may be associated with the learning-retention process over the course of the program, particularly stimulated by the learning transfer phase followed the virtual exposure. This cumulative effect would explain the increasing familiarity with the game tasks and sense of security during their execution, as already demonstrated by patients after the second session, when they began to show greater concern with the score obtained than with possible risks of fall. Indeed, in a later phase of the experiment, participants started to consider not only their individual scores in each game, but also the scores of other subjects. A sense of competition was created despite the individual nature of the games, an expression of social integration commonly observed in this type of approach (Lewis et al., 2011).

Corporeal awareness, an important motor component, may also be related to the functional progress observed, given that corporeal perception in relation to the environment was intensely stimulated by visual feedback. This suggestion is supported by Boberly (Borbely, Deutsch, Filler, Guarrera-Bowlby, \& Huhn, 2008), whose findings showed gains in visual perception, postural control and functional mobility of a patient with cerebral palsy after Wii training. In respect to the influence of feedback, the games used are part of a commercially available model, designed for healthy populations and not adapted to individuals in neurological treatment. Under these conditions, activities categorized as simple or easy by the console could be extremely difficult for patients, such that inability to perform them properly may be frustrating and negatively affect the course of treatment (Alankus, Kelleher, Lazar, \& May, 2010). Hence, special attention should be given to game selection, observing its cognitive-motor demand, in addition to the user's individual affordance.

\section{Conclusion}

Our findings revealed that virtual reality associated with kinesiotherapy and learning transfer exercises had a positive influence on the rehabilitation process of the individuals under study.

When compared to initial data, the final Berg and FIM scores suggest that the proposed rehabilitation program, using virtual reality as an adjunct to conventional therapy, is potentially effective in improving balance and functionality of post-stroke patients. Significant gains in specific items of both scales showed a possible relationship between the motor effects observed and the constant postural adjustments during the virtual exercises performed on WBB, particularly in the anteroposterior and lateral direction, in association with continuous visual feedback modulation.

In conclusion, this study established the feasibility of a VRbased rehabilitation program. It indicated the Nintendo Wii as an affordable alternative for virtual reality interventions and an additional tool in conventional clinical practice, although further investigations on the issue are needed.

\section{References}

Adamovich, S.V., Boaian, R., Burdea, G.C., Jack, D., Merians, A.S., \& Tremaine, M. (2002). Virtual reality - Augmented rehabilitation for patients following stroke. Physical Therapy, 82, 898-915. 
Alankus, G., Kelleher, C., Lazar, A., \& May, M. (2010). Towards Customizable Games for Stroke Rehabilitation. Proceedings of the $28^{\text {th }}$ international conference on human factor in computing systems, Atlanta, Georgia, USA, (ACM), 2113-2122.

Araujo, M.C., Barcala, L., Colella, F., Oliveira, C.S., \& Salgado, A.S.I. (2011). Análise do equilíbrio em pacientes hemiparéticos após treino com o programa Wii Fit. Fisioterapia e Movimento, 24, 337-43.

Austin, J., \& Sigurdsson, O.S. (2008). Using real-time visual feedback to improve posture at computer workstations. Journal of applied behavior analysis, 41, 365-375.

Battistella, L.R., Jucá, S.S. H., Miyazaki, M.H., Pinto, P.P.N., Riberto, M.,\& Sakamoto, H. (2004). Validação da versão brasileira da Medida de Independência Funcional. Acta Fisiatrica, 11, 72-76.

Bayley, M., Cohen, L.G., Hall, J., Mamdani, M., Saposnik, G., Teasell, R., \& Thorpe, K.E. (2010). Effectiveness of virtual reality exercises in stroke Rehabilitation (EVREST): rationale, design, and protocol of a pilot randomized clinical trial assessing the Wii gaming system. International Journal of Stroke, 5, 47-51.

Belgen, B., Beninato, M., Sullian, P.E., \& Narielwalla, K. (2006). The association of balance capacity and fall self-efficacy with history of falling in community dwelling people with cronic stroke. Archives of Physical Medicine and Rehabilitation, 87, 554-561.

Benda, R.N. (2006). Sobre a natureza da aprendizagem motora: mudança e estabilidade...e mudança. Revista Brasileira de Educação Física e Esporte, 20, 43-45.

Berg, K.O., Lombardi Junior, I., Miyamoto, S.T., Natour, J., \& Ramos, L.R. (2004). Brazilian version of the BERG balance scale. Brazilian Journal of Medical and Biological Research, 37, 1411-1421.

Bernal-Sahún, A., De laPeña-González, A.I., De los Reyes-Guzmán, A., Gil-Agudo, A., Peñasco-Martín, B., \& Pérez-Aguilar, B. (2010). Aplicación de larealidad virtual em los aspectos motores de la neurorrehabilitación. Revista de Neurologia, 51, 481-488.

Bonan, I.V., Colle, F.M., Einsenfisz, M., Guichard, J.P., Huy, T.B.,Viacut, E., \& Yelnik, A.P. (2004). Reliance on visual information after stroke Part I: Balance on Dynamic Posturography. Archives of Physical Medicine and Rehabilitation, 85, 268-273.

Borbely.M., Deutsch. J.E., Filler, J., Guarrera-Bowlby, P., \& Huhn, K. (2008). Use of a low-cost, commercially available gaming console (wii) for rehabilitation of an adolescent with cerebral palsy. Physical Therapy Journal, 88, 1196-1207.

Botelho, S.S.C., \& Vaghetti, C.A.O. (2010). Ambientes virtuais de aprendizagem na educação física: uma revisão sobre a utilização de exergames. Ciências e cognição, 15, 76-88.

Brault, S., Craig, C., Ferguson, S., \& Young, W. (2011). Assessing and training standing balance in older adults: A novel approach using the 'Nintendo Wii' Balance Board. Gait \& Posture, 33, 303-305.

Fung, J., Lamontagne, A., Malouin, F., McFadyen, B.J., \& Richards, C.L. (2006). A treadmill and motion coupled virtual reality system for gait training post-stroke. Cyber Psychology and Behavior, 9, 157-162.

Gil-Gómez, J.A., Lloréns, R., Alcañiz, M., \& Coomer, C. (2011). Effectiveness of a Wii balance boad-based system (eBaVir) for balance rehabilitation: a pilot randomized clinical trial in patients with acquired brain injury. Journal of Neuroengeneering and Rehabilitation, 23, 8-30.

Kaefer, A., Chiviacowsky. S., Meira Jr, C.M. \& Tani, G. (2014). Self-Controlled practiceEnhances Motor Learning in Introverts and Extroverts, Research Quarterly for Exercise and Sport, 85, 226-233.

Lavados, P.M., Hennis, A.J., Fernandes, J.G., Medina, M.T., Legetic, B., Hoppe, A., ... Salinas, R. (2007). Stroke epidemiology, prevention, and management strategies at a regional level: Latin America and the Caribean. Lancet neurology, 6, 362-372.

Laver, K., George, S., Thomas, S., Deutsch, J.E., \& Crotty, M. (2012). Cochrane review: virtual reality for stroke rehabilitation. European Jornal of Physical Rehabilitation Medicine, 48, 523-530.

Levac, D.E., \& Galvin, J. (2013). When is virtual reality therapy? Archives of Physical Medicine and Rehabilitation, 94, 795-798.

Lewis, G.N., McPherson, K.M., Rosie, J.A., \& Woods, C. (2011). Virtual reality games for rehabilitation of people with stroke: perspectives from the users. Disability and Rehabilitation: Assistive Technology, 6, 453-463.

Li, Z., Han, X.G., Sheng, J., \& Ma, S.J. (2015). Virtual reality for improving balance in patients after stroke: a systematic review and meta-analysis. Clinical Rehabilitation, 3, 1-9.

Linder, A., Milidonis, M., Reinthal, A., \& Szirony, K. (2010). Use of video gaming as an adjunct during outpatient stroke rehabilitation to obtain upper extremity task specific practice and improve sitting balance. Cleveland State University CSM handouts, 1-177.

Mouawad, M.R., Doust, C.G., Max, M.D., \& McNulty, P.A. (2011). Wii-based movement therapy to promote improved upper extremity function post-stroke: a pilot study. Journal of Rehabilitation Medicine, 43, 527-533.

Newton, M., \& Russel, W.D. (2008). Short-term psychological effects or interactive video game technology exercise on mood and attention. Educational Technology and Society, 11, 294-308.

Nichols-Larsen, D.S., Clark, P.C., Zeringue, A., Greenspan, A., \& Blanton, S. (2005). Factors influencing stroke survivor's quality of life during subactue recovery. Stroke, 36, 1480-1484.

Rizzo, A.A., \& Schultheis, M.T. (2001). The application of virtual reality technology in rehabilitation. Rehabilitation Psychology, 46, 296-311.

Schiavinato, A.M., Baldan, C., Melatto, L., \& Lima, L. (2010). Influência do Wii Fit no equilíbrio de paciente com disfunção cerebellar: estudo de caso. Journal of Health Sciences Institute, $28,50-52$. 


\section{Author's note}

Wagner Henrique Souza Silva, PhD fellow., MSc., BSc., PT. Integrated Program in Neurosciences, Faculty of Medicine-McGill University. McGill University: 3205, Place Alton Goldbloom - Chomedey, Laval. Québec. H7V 1R2

Wagner Henrique Souza Silva, Gleyson Luiz Bezerra Lopes, Kim Mansur Yano, Nathália Stephany Araújo Tavares, Isabelle Ananda Oliveira Rego, and Fabrícia Azevedo da Costa Cavalcanti are affiliated with the Federal University of Rio Grande do Norte: Department of Physical Therapy, Av. Senador Salgado Filho, 3000, Post Office Box: 1524, Natal, Rio Grande do Norte. 59072-970, Brazil

\section{Corresponding author:}

Wagner H Souza Silva

150 Rue St. Norbert. \#412. Montreal, QC. H2X 1G6. Canada.

Manuscript received on March 17, 2014

Manuscript accepted on August 11, 2015

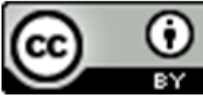

Motriz. The Journal of Physical Education. UNESP. Rio Claro, SP, Brazil - eISSN: 1980-6574 - under a license Creative Commons - Version 3.0 